\title{
Diversity of floral visitors to sympatric Lithophragma species differing in floral morphology
}

\author{
Mariana Cuautle $\cdot$ John N. Thompson
}

Received: 30 March 2009/Accepted: 14 July 2009/Published online: 11 August 2009

(C) The Author(s) 2009. This article is published with open access at Springerlink.com

\begin{abstract}
Most coevolving relationships between pairs of species are embedded in a broader multispecific interaction network. The mutualistic interaction between Lithophragma parviflorum (Saxifragaceae) and its pollinating floral parasite Greya politella (Lepidoptera, Prodoxidae) occurs in some communities as a pairwise set apart from most other interactions in those communities. In other communities, however, this pair of species occurs with congeners and with other floral visitors to Lithophragma. We analyzed local and geographic differences in the network formed by interactions between Lithophragma plants and Greya moths in communities containing two Lithophragma species, two Greya species, and floral visitors other than Greya that visit Lithophragma flowers. Our goal was to evaluate if non-Greya visitors were common, if visitor assembly differs between Lithophragma species and populations and if these visitors act as effective pollinators. Sympatric populations of L. heterophyllum and L. parviflorum differ in floral traits that may affect assemblies of floral visitors. Visitation rates by non-Greya floral visitors
\end{abstract}

Communicated by Jeff Karron.

M. Cuautle $(\varangle) \cdot$ J. N. Thompson

Department of Ecology and Evolutionary Biology,

University of California, A316 Earth and Marine

Sciences Building, Santa Cruz, CA 95064, USA

e-mail: mariana.cuautle@udlap.mx;

mcuautle2004@hotmail.com

J. N. Thompson

e-mail: thompson@biology.ucsc.edu

Present Address:

M. Cuautle

Departamento de Ciencias Químico-Biológicas,

Universidad de las Américas-Puebla, Cholula,

Puebla 72820, Mexico were low, and the asymptotic number of visitor species was less than 20 species in all populations. Lithophragma species shared some of the visitors, with visitor assemblages differing between sites more for L. heterophyllum than for $L$. parviflorum. Pollination efficacy experiments showed that most visitors were poor pollinators. Single visits to flowers by this assemblage of species resulted in significantly higher seed set in Lithophragma heterophyllum (30.6 \pm 3.9 SE) than in L. parviflorum (4.7 $\pm 3.4 \mathrm{SE})$. This difference was consistent between sites, suggesting that these visitors provide a better fit to the floral morphology of L. heterophyllum. Overall, none of the nonGreya visitors appears to be either sufficiently common or efficient as a pollinator to impose strong selection on any of these four Lithophragma populations in comparison with Greya, which occurs within almost all populations of these species throughout their geographic ranges.

Keywords California - Geographic variation - Greya . Pollinator efficacy · Interaction network

\section{Introduction}

As evidence of coevolution has accumulated, it has become clear that most coevolving relationships between pairs of species are shaped by interactions with yet other taxa. Even the most commonly cited examples of extreme coevolution between pairs of species are known to be molded by a broader network of interactions. Examples include nematodes that attack pollinating fig wasps (Herre 1993), co-pollinators that alter one-to-one mutualism between particular pollinators and plants (Thompson and Cunningham 2002), and squirrels that can locally disrupt coevolution between lodgepole pines and crossbills (Benkman et al. 
2001). The effect of other species on pairwise interactions often varies among populations, creating the potential for a multispecific geographic mosaic of coevolution in many interactions (Thompson 1994, 2005).

In some interactions, such as pollination mutualisms, these geographically varying networks of species develop through a combination of diversification of closely related taxa and convergence of traits of unrelated species (e.g., "pollination syndromes"). In fact, recent analyses of pollination and other mutualistic networks have shown that such mutualisms among free-living species often result in much less compartmentalization than occurs in antagonistic interactions such as those between predators and prey (Bascompte et al. 2003; Jordano et al. 2003; Guimarães et al. 2006; Lewinsohn et al. 2006). There is, however, always some compartmentalization in mutualistic networks. Many of these networks include modules composed of a closely related group of species (e.g., two or more congeneric plant species) that interacts with another group of closely related species (e.g., two or more congeneric pollinator species). The number of species involved in these mutualistic modules often varies geographically, ranging from a simple pairwise interaction in some communities to trios, quartets, or larger sets of interacting species in other communities. As these interactions continue to diversify through speciation and secondary contact, they could either continue to coevolve as a tight mutualistic network or change fundamentally in ways that allow incorporation of other, unrelated species into the interaction.

Here, we evaluate if a pairwise pollination mutualism has diversified to incorporate unrelated species as the mutualistic pair has undergone speciation and then reassembled in local communities as small sets of coexisting congeners. Specifically, we analyze local and geographic differences in the floral visitor network formed by two species of woodland star, Lithophragma heterophyllum and L. parviflorum (Saxifragaceae), and their assemblages of floral visitors. The two Lithophragma species differ in multiple floral traits, and they co-occur in communities that differ in overall floristic and faunistic composition, providing an opportunity to evaluate how divergence in traits and community context may have reshaped the role of co-pollinators in these interactions.

One of these species, L. parviflorum, has previously been shown to have a strongly mutualistic relationship with a pollinating floral parasitic moth, Greya politella (Prodoxidae), in some ecosystems in the North American Pacific Northwest where co-pollinators are uncommon and there are no co-occurring Lithophragma species that are visited by Greya (Thompson and Pellmyr 1992; Pellmyr and Thompson 1996; Thompson and Cunningham 2002; Thompson and Fernandez 2006). The interaction between
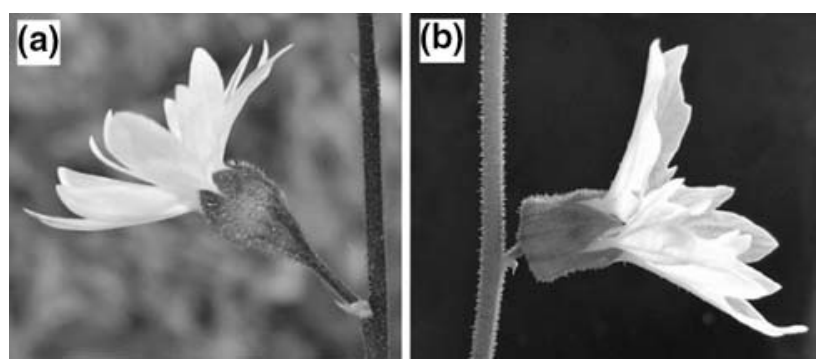

Fig. 1 Photographs of a Lithophragma parviflorum and b Lithophragma heterophyllum, showing differences in floral morphology between species. In both species floral length from the top of the sepals to the base of the ovary is approximately $6 \mathrm{~mm}$

the moths and the plants ranges among habitats from mutualistic to commensalistic to antagonistic, depending on the presence of co-pollinators. In parts of the Coast Ranges of California, the network structure of the interaction is more complex. Some ecosystems have two to three co-occurring Lithophragma species that are visited by Greya moths and occasionally by other floral-visiting taxa. These co-occurring Lithophragma species are similar in many traits but differ in others, including the degree of inferiority of the ovary within the flower, floral scent, and width of the corolla opening (Fig. 1; Taylor 1965; Kuzoff et al. 1999). These differences in floral traits may contribute to differential visitation by floral visitors and subsequent selection on the evolution of floral morphology.

We assessed visitation patterns to Lithophragma species in two widely separated communities where $L$. heterophyllum and L. parviflorum are sympatric. In both communities, Greya moths visit the flowers of both species and then lay their eggs in the plant tissues. They spend much of their adult lives either nectaring, resting, or ovipositing on their hostplants. In the year of this study, $77-90 \%$ of L. parviflorum plants received Greya eggs and 16-21\% of $L$. heterophyllum plants received eggs (K. Rich and J. N. Thompson, unpublished data). Our goal was to evaluate whether non-Greya floral visitors are also common visitors to these plants, whether their visitation patterns differ between the two Lithophragma species, whether the patterns were similar in the two communities, and whether the most common of these visitors could act as effective pollinators as has been shown in some northern regions where only L. parviflorum occurs.

\section{Materials and methods}

Lithophragma (Saxifragaceae) is endemic to western North America, comprising seven to nine species (Taylor 1965; Kuzoff et al. 1999). Lithophragma parviflorum, which is the most derived species within the genus (Kuzoff et al. 
1999), has the widest geographic distribution and encompasses the ranges of most of the other Lithophragma species. It occurs in steppe, grasslands, savannas, and woodlands from southern British Columbia to California and eastward into the Rocky Mountains. Several subspecies have been recognized and these have sometimes been considered as separated species, but molecular studies (Kuzoff et al. 1999) and crossing studies (S. Dwiggins and J. N. Thompson, unpublished data) have indicated that these populations form a single biological species. In contrast, Lithophragma heterophyllum, which is a more basal species within the genus (Kuzoff et al. 1999), is restricted mostly to woodlands in the Coast Ranges of California. It usually grows in partly or fully shaded, welldrained slopes of oak or mixed coniferous-oak woodland, extending up to $1,370 \mathrm{~m}$ elevation.

These two Lithophragma species are sympatric at multiple sites throughout the Coast Ranges, but differ in multiple floral characters (Fig. 1). Lithophragma parviflorum plants produce one or more floral stalks, arising from a basal rosette of leaves. Each stalk produces two to ten tubular flowers that open sequentially. Individual flowers have an inferior ovary and a Franciscan stigma that is receptive only around the sides of the top edge, and a narrow corolla (Taylor 1965; Kuzoff et al. 2001). The 11- to 15-mm-wide corolla has five petals that are flattened at the top to form a platform that is used during visits by some flower visitors. A narrow corolla opening forms a long tube (up to $2.5 \mathrm{~mm}$ ) above the inferior ovary, which contains 150-400 ovules. The number of ovules per flower varies with growing conditions and position on the inflorescence, with smaller plants and later flowers producing fewer ovules (Thompson and Pellmyr 1992; Pellmyr and Thompson 1996). Halfway down the corolla tube, the stigmas flare at the top of the long and fused styles at about the same level as the ten anthers. After pollination, the seeds mature over the next several weeks, and the plants then die back to the ground surface. In late fall or early winter, new leaves are produced from underground bulbils. The plants remain in this vegetative state until the spring, when they flower again (Thompson and Pellmyr 1992).

Lithophragma heterophyllum flowers have a pseudosuperior ovary, a stigma that is receptive over the entire top surface, and a wide corolla opening (Fig. 1; Taylor 1965; Thompson 1997; Kuzoff et al. 2001). Each plant produces one to several floral stalks, often many branched, arising from a basal rosette. Each inflorescence usually has three to six flowers, each containing up to 490 ovules. The flowers open from bottom to top. The stigmas are not as flared at the top of the fused styles as they are in L. parviflorum. After pollination, the seeds mature over the next several weeks, and the plants then die back to the ground surface. In late fall or early winter, new leaves are produced from underground bulbils. The plants remain in this vegetative state until the spring, when they flower again.

In both Lithophragma species, individual flowers remain open for only a few days. Unpollinated flowers soon wither as the plant produces new flowers higher up on the floral scape.

\section{Study sites}

The study was conducted at the Hopland Research and Extension Center (hereafter Hopland) and at the Hastings Natural History Reservation (hereafter Hastings) where L. parviflorum and L. heterophyllum populations are sympatric. Hopland $\left(38^{\circ} 59^{\prime} 00^{\prime \prime} \mathrm{N}, 123^{\circ} 05^{\prime} 30^{\prime \prime} \mathrm{W}\right)$ is situated in the foothills of the Mayacamas Mountains, part of the Coast Ranges of California north of San Francisco Bay. The climate is Mediterranean with hot, dry summers (June through September) reaching $33^{\circ} \mathrm{C}$, and mild, rainy winters (http://groups.ucanr.org/hopland/Natural_Resources/). The vegetation includes a diverse mix of grassland (dominated by the herb Aegilops triuncialis), oak woodland dominated by Quercus ( $Q$. douglasii, $Q$. kelloggii, Q. lobata, $Q$. wislizenii), dense woodland (Q. kelloggii, Q. wislizenii,), and chaparral (characterized by the shrubs Adenostoma fasciculatum, Ceanothus cuneatus and by $Q$. durata). Vernal pools and meadows, perennial wetlands (riparian, sag pond), serpentine areas, and outcrops occur throughout the area (K. Heise, in preparation).

Hastings $\left(36^{\circ} 12^{\prime} 30^{\prime \prime} \mathrm{N}, 121^{\circ} 33^{\prime} 30^{\prime \prime} \mathrm{W}\right)$ is located in the Sierra de Salinas, on the most northerly end of the Santa Lucia Range that includes the Big Sur wilderness of central, coastal California. The climate is moderate, with cool winters and with late summer air temperatures reaching as high as $38^{\circ} \mathrm{C}$. Level fields are rare and small. The vegetation types comprise hard chaparral (Adenostoma spp.), a mix of blue oak (Quercus douglasii) and scattered native savanna (characterized by the herb Nassella pulchra), mixed woodlands of live oak ( $Q$. agrifolia), riparian forests dominated by valley oak (Q. lobata), live oak, and willow (Salix sp.) with sycamore (Platanus sp.), and old fields dominated by non-native annual grasses (http://www. hastingsreserve.org).

Insect assemblage structure

Insect visits to naturally occurring plants and greenhousegrown plants were recorded throughout the season at both study sites. Observations were made from 0900 to 1700 hours, when the weather conditions were favorable for insect flight activity. Greya moths are strictly diurnal and are generally active from mid-morning through midafternoon. Observations have shown no evidence of activity by floral visitors to these Lithophragma species 
during the generally cool to cold evenings and nights in the early spring when these plants flower (J. N. Thompson, personal observation). During the observation periods, the identity of floral visitors and the rate of visitation to field plants were assessed by recording all visits to flowers within $4 \mathrm{~m}^{2}$ quadrats at the two sites (4 quadrats/site/species, 2-4 days of observation/site/species; mean $\pm \mathrm{SD}$ plants per quadrat $9 \pm 5$; mean \pm SD flowers per quadrat $21 \pm 14$; all observations performed by one person). The total number of hours of pollinator observation for field and greenhouse-grown plants for L. heterophyllum was 29.31 and $25.56 \mathrm{~h}$ at Hastings and Hopland, respectively, and for L. parviflorum was 27.17 and $19.23 \mathrm{~h}$ for the same sites. The hours of observation differed between sites and species, because they depended on the availability of open flowers for both greenhouse-grown plants and field plants, as well as on weather conditions.

\section{Visitation rate}

Visitation rate was calculated as the number of visits per hour per quadrat divided by the number of flowers in that quadrat. The data were Box-Cox transformed to meet assumptions of normality. Analysis of variance was used to analyze the effects of plant species, study site, and species $\times$ site interaction on visitation rates. All analyses were performed using JMP 5.0.1a software (JMP 2002). Insect vouchers were deposited within the Thompson laboratory insect collection at the University of California, Santa Cruz.

Insect assemblage: similarity and richness

The similarity and richness of the visitor assemblies were compared using abundance based estimator indices and sample-based rarefaction curves respectively, using the program EstimateS 7.5 (Colwell 2005). Two similarity indices were used: Chao-Jaccard $\left(\wedge \mathrm{J}_{\mathrm{abd}}\right)$ and ChaoSorensen $\left(\wedge \mathrm{L}_{\mathrm{abd}}\right)$. These two indices are probabilisticbased indices that consider abundances and take into account unseen shared species (i.e., species actually present at both sites but not detected in one or two of the samples). These indices have proven to be considerably less biased than classic indices when samples differ in number of observations, are known or suspected to be under-sampled, or are likely to contain numerous rare species (Chao et al. 2005). The indices range from 0 (completely dissimilar) to 1 (identical).

Pollinator species richness was compared using samplebased rarefaction curves at common levels of abundance for all sites and species combinations. Species accumulation curves of the number of observed species, plotted as a function of the sampling effort required to observe this number of species, have been used in previous studies to compare richness in different areas (Colwell and Coddington 1994; Colwell et al. 2004). The sequential accumulation of individuals in a single sample, or the successive pooling of samples from a single sample set, produces a species accumulation curve, but it is not a smooth curve due to spatial (or temporal) patchiness and simple stochastic effects. Rarefaction curves permit comparison of different assemblages at comparable levels of sampling effort (Colwell and Coddington 1994; Colwell et al. 2004).

The sample-based rarefaction curves were computed with the EstimateS 7.5 software, which uses the analytical formulas of Colwell et al. (2004). These algorithms interpolate values between zero and the observed number of samples, and compute the expected richness and its confidence intervals, thereby permitting direct statistical comparison of richness among datasets. This method replaces the resampling technique used in previous version of EstimateS. The expected richness function is called Mao Tau (Colwell 2005). As recommended by Gotelli and Colwell (2001), we re-scaled these accumulation (Mao Tao) curves based on the number of individuals rather than on the number of samples, which allowed us to compare the same number of sampled individuals in each analysis. This procedure allowed comparisons at the same level of sampling intensity for each site and species.

\section{Pollinator efficiency experiment}

Although the number of visits to these flowers is very low, we undertook a preliminary study of the efficacy of most non-Greya visitors to plants set out within natural communities. This procedure works well for insects that continually move among flowers, but not for Greya moths, which spend most of their lives resting on Lithophragma flowers and only occasionally move among flowers during their diurnal flight period. Evaluation of efficacy for Greya requires alternative protocols that have been used in earlier experiments, which have shown that $G$. politella moths are highly effective pollinators (Thompson and Pellmyr 1992; Pellmyr and Thompson 1996; Thompson and Cunningham 2002). The experiments therefore did not include Greya because the goal of this particular study was to assess the commonness and potential effectives of the other floral visitors that may affect the evolution and ecology of the mutualism between Greya moths and Lithophragma plants.

Efficiency was measured as the number of seeds resulting from a single visit by one visitor to a receptive flower that had never previously been visited. For these experiments, seeds and underground bulbils were collected at the field sites in spring 2004. Five to six seeds or five bulbils per pot were germinated on the surface of (damp) 
HP Promix soil. There were 21 maternal lineages (i.e., seeds or bulbils collected from an individual plant) for L. parviflorum from Hopland, 11 for L. parviflorum from Hastings, 18 for L. heterophyllum from Hopland and 20 for L. heterophyllum from Hastings. These pots were put into incubators until the 14th day, on a 10:14 h light:dark cycle at $15^{\circ} \mathrm{C}$ during the day and $10^{\circ} \mathrm{C}$ at night. There were two sowing periods for each species and site, with a gap of 2 weeks between them. The whole sowing period was from 29 November to 16 December 2004. Six or eight weeks after sowing, seedlings were transplanted to individual pots. Transplants were performed from 7 January to 19 February 2005. Transplanted plants were put into growth chambers for a week (14th day, $10 \mathrm{~h}$ cycle at $15^{\circ} \mathrm{C}$ during day and $10^{\circ} \mathrm{C}$ at night), and then moved to a greenhouse on the 14 th day on a $10 \mathrm{~h}$ cycle at $15^{\circ} \mathrm{C}$ during day and $10^{\circ} \mathrm{C}$ at night). Plants were watered every other day and fertilized twice, approximately 2 and 6 weeks after transplanting, with 50 ppm Peter's fertilizer.

The greenhouse plants were transported at their peak of flowering to the field sites and kept in outdoor mesh cages $(1.82 \times 3.66 \times 1.82 \mathrm{~m})$ (Hastings) or in a greenhouse (Hopland) until the time they were put in the field. For the experiments, the plants were placed amid flowering L. heterophyllum or L. parviflorum plants in the field to assess patterns of visitation by insects, and also to assess the pollination efficiency of floral visitors. Although, there is some degree of overlap in the habitat in which L. parviflorum and L. heterophyllum grow, they were usually separated by tens of meters at our study sites. Consequently, there was little movement of floral visitors between the two species as they moved among plants.

The experiments were carried out from the middle of March to the middle of May 2005. This period spanned most of the flowering period. Flats containing 7-14 greenhouse plants were set out within either a L. heterophyllum or L. parviflorum natural population and observed until an insect visited one or more flowers of the plants. Immediately after insect departure, the petals of visited flowers were marked with felt-tip ink pens in a fixed color that corresponded to the visitor identity and the hour and visitor species noted. Repeated visits to individual flowers were not permitted. Hence, the seeds produced in a specific capsule resulted from a single visit by an insect visitor to a flower that had not been visited previously by any other insect. The flower and the branch were tagged with a sequential number series that linked it to the information of the visitor and hour. While in the field, plants not being used at that moment in an efficacy trial were kept to a polyester mesh cage $(1 \times 1 \mathrm{~m})$ free of all insects. Plants used once were not used again and were returned to the greenhouse at the end of the day. The total number of flowers visited during the observations periods (see insect assemblage structure) for $L$. heterophyllum were 43 at Hastings and 54 at Hopland; and for L. parviflorum, 57 and 86 , respectively. Capsules were collected 9 days after the petals of visited flowers began to shrivel or fall off and then dissected under a dissecting microscope to determine the number of developing seeds.

\section{Seed production and proportions of seeds developing}

The probability that a visited flower produced any seed was determined for each Lithophragma species at each site. Also, for those flowers that produced seed, the total number of seeds and the proportions of seeds developing with respect to total ovules, were compared. We assessed whether the likelihood that a flower produced seed depended on the Lithophragma species, the site, or the interaction of species and site using a nominal logistic model in the JMP 5.0.1a software package (JMP 2002). Because seed number data (including those capsules that did not produce any seed) could not be transformed to achieve normality, the $P$ values reported for these results are from randomization tests on 10,000 iterations performed with SAS PROC MIXED using a macro wrapper (Cassell 2002; Hoeksema and Thompson 2007). Data on seed number, using only those capsules that produced at least one seed and the seed proportions were Box-Cox transformed to meet assumptions of normality and homoscedasticity, and ANOVAs were performed to probe for species, site or an interaction effect.

\section{Results}

\section{Visitation rates}

The number of visits per hour to a flower was low, except for L. parviflorum at Hopland (Fig. 2). The analysis of variance showed a significant species by site interaction effect $\left(F_{1,45}=13.83, P=0.0006\right)$, indicating that $L$. heterophyllum flowers are visited very infrequently at both sites (visits/flower/h mean $\pm \mathrm{SE}$ : Hastings $0.10 \pm 0.04$ vs Hopland $0.13 \pm 0.04$ ), but $L$. parviflorum flowers at Hopland were significantly more visited than those at Hastings $(1.52 \pm 0.36$ vs $0.07 \pm 0.02, \quad P<0.05, \quad Q=2.6677$ Tukey-Kramer HSDTest). Also, L. parviflorum flowers at Hopland were significantly more visited than flowers on L. heterophyllum in either of the two populations $(P<0.05, Q=2.6677$ Tukey-Kramer HSDTest).

Pollinator species similarity and richness

Few non-Greya visitor species were attracted to either Lithophragma species. The number of visitor species 


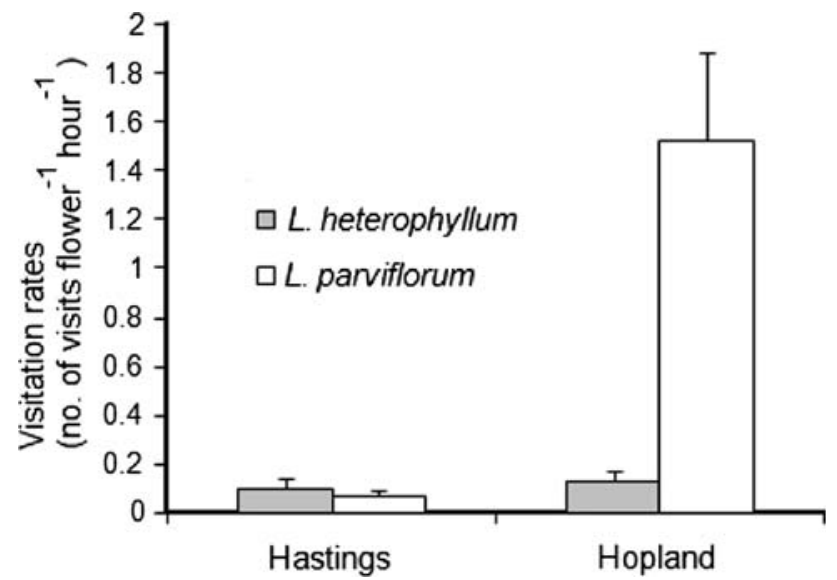

Fig. 2 Visitation rates by floral visitors to L. heterophyllum (filled bars) and $L$. parviflorum (open bars) at the two study sites. Lithophragma parviflorum plants in Hopland were the most visited $\left(F_{1,45}=13.83, P=0.0006\right.$, ANOVA). $n=49 \mathrm{~h}$

ranged from a low of 8 to $L$. heterophyllum at Hastings to a high of 17 to L. parviflorum at Hastings (Table 1). These numbers include the few instances in which Greya individuals moved during these observation periods; Greya adults often move among plants only a few times a day. Chao-Jaccard and Chao-Sorensen similarity indices showed that, at both sites, L. parviflorum and L. heterophyllum shared some of the available pollinators in the community (Fig. 3). For example, both Lithophragma species shared the same main non-Greya visitor at each site: the fly Eristalis hirta at Hastings and the bee Andrena nigrocaerulea at Hopland. Some, but not all, of the major visitors at Hopland were similar to those observed at Hastings. The visitor assemblage to L. heterophyllum differed significantly between sites (Fig. 3). In contrast, the visitor assemblage to $L$. parviflorum was more similar between sites (Fig. 3).

Lithophragma parviflorum at Hastings attracted a greater number of insect species than the other Lithophragma populations, as indicated by the accumulation (Mao Tao) curves for the different plant species and sites (Fig. 4). When the curves were compared for the number of species observed among 40 individuals (which is the greatest abundance value common to all sites and species combinations), the number of species for $L$. parviflorum at Hastings was significantly higher $(13.11 \pm 1.27 \mathrm{CI})$ than for any other population [ $L$. heterophyllum Hastings $(9 \pm 1.31 \mathrm{CI}), \quad$ L. heterophyllum $(10.02 \pm 0.96 \mathrm{CI})$, L. parviflorum Hopland $(9.24 \pm 1.27 \mathrm{CI})]$. Overall, the curves indicate that fewer than 20 insect species are likely to visit either of these Lithophragma species at these field sites, and most are rare visitors (Fig. 4).
Mean number of seeds per visit

Of the 241 visits during the efficacy trials, only a few visitors were able to pollinate the flowers (Table 1). The low visitation rate by non-Greya pollinators restricted the opportunity to obtain robust estimates of pollination efficacy for each visitor species on each plant population. The few visits by Greya during these trials indicated that G. obscura and G. politella males are also poor pollinators when nectaring on flowers. That result in consistent with past work showing that G. politella is an effective pollinator primarily when it is ovipositing through the corolla (Pellmyr and Thompson 1996; Thompson and Pellmyr 1992).

The mean number of seeds produced by the three relatively common floral visitors, A. nigrocaerulea, E. hirta, and Toxomerus spp., differed depending on the plant species and site combination (Fig. 5; Table 2). For most of the visitors, visitation rate was too small for evaluation to assess pollination efficacy.

During the efficacy trails, $L$. heterophyllum flowers had a higher probability of producing seeds after a single visit than L. parviflorum (Fig. 6). In addition, L. heterophyllum produced on average a higher number of seeds than L. parviflorum (Table 3 ). This result remained even if the data were restricted only to those capsules that produced one or more seeds and also if the response variable was seed proportions (Table 3). There were no significant site or interaction effects in these analyses.

\section{Discussion}

The field observations and experiments showed that fewer than 20 non-Greya insect species visit Lithophragma in these communities. These floral visitors differ considerably in pollination efficacy, as is commonly observed in pollination efficacy studies (Thompson and Pellmyr 1992; Pellmyr and Thompson 1996; Wallace et al. 2002; Kephart and Theiss 2004; Fenster et al. 2004). Even the relatively efficient species, however, are unlikely to be major pollinators of Lithophragma, given the observed low rates at which each of these species visits flowers. Multiple visitor species visited both Lithophragma species at both sites. This result was, to some extent, unexpected because $L$. parviflorum and $L$. heterophyllum differ in floral morphology, and congeneric plant species can sometimes differ considerably in the floral visitors they attract (Borba and Semir 2001; Kephart and Theiss 2004; Ippolito et al. 2004; Mant et al. 2005; Streisfeld and Kohn 2007; Wolfe and Sowell 2006). 
Table 1 Total number of visits and seeds produce mean \pm SE, except for those with just one visit to L. heterophyllum and L. parviflorum by each visitor species to experimental flowers during efficacy experiments

\begin{tabular}{|c|c|c|c|c|c|c|c|c|}
\hline & \multicolumn{4}{|c|}{ Hastings } & \multicolumn{4}{|c|}{ Hopland } \\
\hline & \multicolumn{2}{|c|}{ L. heterophyllum } & \multicolumn{2}{|c|}{ L. parviflorum } & \multicolumn{2}{|c|}{ L. heterophyllum } & \multicolumn{2}{|c|}{ L. parviflorum } \\
\hline & Visits & Seed & Visits & Seed & Visits & Seed & Visits & Seed \\
\hline \multicolumn{9}{|l|}{ Hymenoptera } \\
\hline Andrena nigrocaerulea & & & 4 & 0 & 21 & $17.8 \pm 23.4$ & 28 & $12.7 \pm 4.1$ \\
\hline Ceratina acantha & 1 & 0 & 3 & $1.0 \pm 1.0$ & & & & \\
\hline Lasioglossum sp. 2 & & & & & 3 & $9 \pm 1.2$ & 7 & $0.6 \pm 0.4$ \\
\hline Lasioglossum sp. 1 & & & & & 1 & 300 & & \\
\hline Bee $1^{\mathrm{a}}$ & 1 & 79 & & & & & & \\
\hline Bee $2^{\mathrm{a}}$ & & & 1 & 1 & & & & \\
\hline Bee $3^{\mathrm{a}}$ & & & 1 & 8 & & & & \\
\hline Bee $4^{\mathrm{a}}$ & & & 1 & 1 & & & & \\
\hline Bee $5^{\mathrm{a}}$ & & & & & & & 1 & 0 \\
\hline \multicolumn{9}{|l|}{ Diptera } \\
\hline Thevenetimyia phalantha & & & 1 & 4 & & & & \\
\hline Empididae 1 & & & 8 & 0 & & & & \\
\hline Empididae 2 & & & & & 1 & 4 & & \\
\hline Symphoromya sp. & 6 & $16.3 \pm 13.4$ & 4 & 0 & & & 2 & 0 \\
\hline Scatophaga spp. & & & 1 & 0 & 11 & $7.2 \pm 10.7$ & 7 & $0.2 \pm 0.3$ \\
\hline Bombylius major & 1 & 5 & & & 5 & 0 & 12 & $5.9 \pm 4.4$ \\
\hline Conophorus obesulus & & & 1 & 164 & & & & \\
\hline Eristalis hirta & 25 & $19.6 \pm 6.3$ & 12 & 0 & & & 1 & 0 \\
\hline Eupeodes volucris & 1 & 0.8 & 3 & $1.0 \pm 1.0$ & & & 1 & 0 \\
\hline Platycheirus obscurus & & & & & 1 & 6 & 1 & 0 \\
\hline Scaeva pyrastri & & & & & 1 & 9 & 5 & 0 \\
\hline Toxomerus spp. & 6 & $35.8 \pm 21.4$ & 2 & $0.5 \pm 0.5$ & 8 & $22.2 \pm 11.9$ & 14 & $2.1 \pm 1.6$ \\
\hline Hydrophoria sp. & & & & & & & 1 & 0 \\
\hline Fly $1^{\mathrm{a}}$ & & & 1 & 0 & & & & \\
\hline Fly $2^{\mathrm{a}}$ & & & & & & & 1 & 0 \\
\hline \multicolumn{9}{|l|}{ Lepidoptera } \\
\hline Greya obscura & & & 9 & 0 & & & 5 & $1.2 \pm 0.8$ \\
\hline Greya politella (female) & & & & & 2 & $68.0 \pm 21.0$ & & \\
\hline Greya politella (male) & & & 3 & 0 & & & & \\
\hline \multicolumn{9}{|l|}{ Coleoptera } \\
\hline Beetle & 1 & 4 & 2 & $1 \pm 1$ & & & & \\
\hline Total visits & 43 & & 57 & & 54 & & 86 & \\
\hline
\end{tabular}

${ }^{\mathrm{a}}$ Not collected

The overall assemblage of co-visitors was similar in some respects but different in other respects from that observed in earlier studies at two sites in Washington State, about 1,200-1,600 km northwest of the sites evaluated in this study (Thompson and Pellmyr 1992; Pellmyr and Thompson 1996; Thompson and Cunningham 2002). Both in California and Washington State, the co-visitors were solitary bees and flies, and some of the same genera were visitors in both regions. These included bees of the genera Andrena and Ceratina, and flies in the genus Bombylius.
California populations, however, were visited by a greater diversity of fly taxa than Washington State populations, where the dipteran visitors were almost exclusively bombyliid flies.

Because visits by non-Greya floral visitors were uncommon, it was not possible to obtain robust sample sizes on pollination efficacy for all visitor species. Although most species appeared to be inefficient at pollinating Lithophragma, there were indications of some differences among the visitor species. Nevertheless, a general 


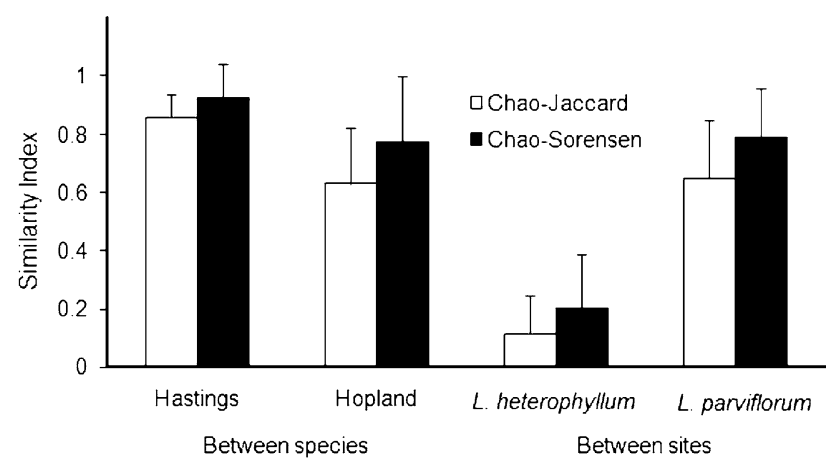

Fig. 3 Chao-Jaccard+ (open bars) and Chao-Sorensen+ (filled bars), similarity indexed comparing visitor assemblies to the two Lithophragma species at the same site (between species) and within Lithophragma species at different sites (between sites). Bars are means $\pm \mathrm{SD}(n=58 \mathrm{~h})$. Visitor assemblies to Lithophragma species were similar at the two sites

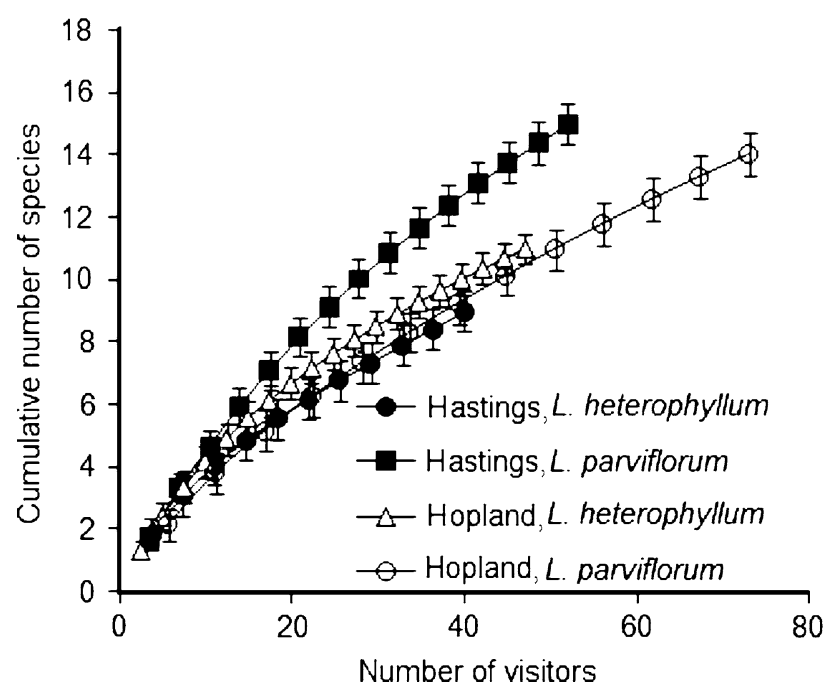

Fig. 4 Cumulative number of visitor species as a function of the number of visitors observed (accumulation Mao Tao curves) to all Lithophragma populations at the two study sites. Lithophragma parviflorum at Hastings had the highest species diversity of visitors. Diversity values are means $\pm 95 \%$ CI

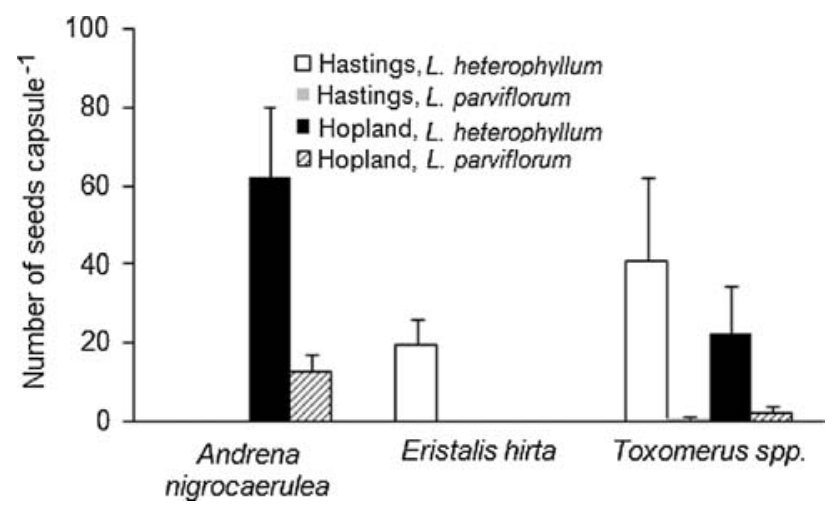

Fig. 5 Seed production (mean + SE) produced after a single visit to a flower by the principal visitors to Lithophragma populations at the two study sites, $n=49,38$ and 30 total capsules for each respective visitor species
Table 2 Results of a Kruskal-Wallis test comparing the number of seeds produced in the four different populations by the main visitors after a single visit

\begin{tabular}{llll}
\hline Visitor species & $\chi^{2}$ approximation & $d f$ & $P$ value \\
\hline Andrena nigrocaerulea & $\mathbf{7 . 6 7}$ & $\mathbf{2}$ & $\mathbf{0 . 0 2 1}$ \\
Bombylius major & 4.84 & 2 & 0.088 \\
Eristalis hirta & $\mathbf{8 . 4 7}$ & $\mathbf{2}$ & $\mathbf{0 . 0 1 4}$ \\
Eupeodes volucris & 2.66 & 2 & 0.26 \\
Scatophaga spp. & 0.79 & 2 & 0.67 \\
Symphoromya sp. & 3.57 & 2 & 0.16 \\
Toxomerus spp. & $\mathbf{9 . 8 7}$ & $\mathbf{3}$ & $\mathbf{0 . 0 1 9}$ \\
\hline
\end{tabular}

Species for which significant differences were found are in bold

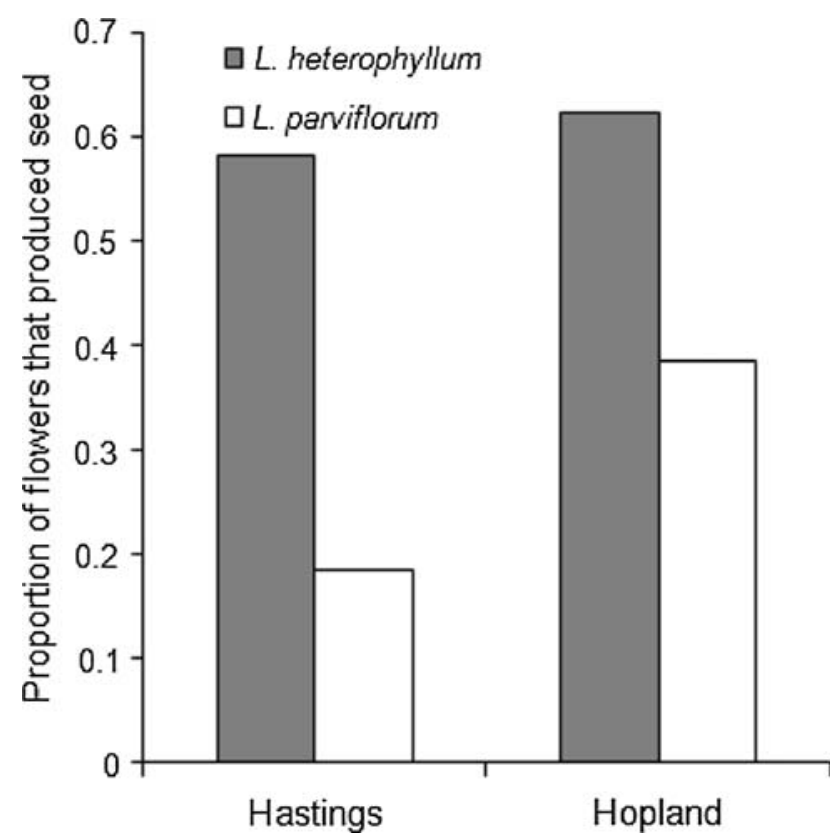

Fig. 6 Proportion of flowers that produced seeds of the total that received a single pollinator visit to L. heterophyllum (filled bars) and $L$. parviflorum (open bars) at the two sites. Species (Wald $\chi^{2}=20.78, d f=1, P<0.0001$ ) and site (Wald $\chi^{2}=4.44, d f=1$, $P=0.035)$ were significant, with higher proportions for $L$. heterophyllum and Hopland plants. Values are proportions. $n=233$ total capsules

and consistent pattern was apparent, even between sites. The visitor assemblies differed strongly in their overall effects on seed set in L. heterophyllum and L. parviflorum. The interaction between $L$. heterophyllum and its pollinators resulted in a higher seed set than for $L$. parviflorum. Several non-Greya species were able to generate seed set in $L$. heterophyllum greater than about 15 seeds during a single visit, whereas that occurred in $L$. parviflorum for only one visit by one non-Greya visitor. The most likely explanation for this difference is that these visitors provide a better fit to the floral morphology of L. heterophyllum than to L. parviflorum at these sites. Large differences in 
Table 3 Results of the ANOVAs comparing the number of seeds per floral capsule produced during experimental visits to Lithophragma flowers, combining visits by all floral visitors

\begin{tabular}{|c|c|c|c|c|}
\hline & L. heterophyllum (mean $\pm \mathrm{SE})$ & L. parviflorum $($ mean $\pm \mathrm{SE})$ & $F$ & $P$ \\
\hline All capsules & $30.6 \pm 3.9$ & $4.7 \pm 3.4$ & $F_{1,227}=23.65$ & $<0.0001$ \\
\hline Capsules that produced seed & $51.0 \pm 7.12$ & $15.5 \pm 10.0$ & $F_{1,96}=22.58$ & $<0.001$ \\
\hline Proportions of seeds developing & $0.11 \pm 0.02$ & $0.04 \pm 0.02$ & $F_{1,96}=16.28$ & $<0.0001$ \\
\hline
\end{tabular}

Differences are also shown for proportions of seeds developing in the two species. Differences between species were determined using randomization tests (based upon 10,000 iterations), performed within SAS PROC MIXED using a macro wrapper (Cassell 2002) for seed number (all capsules)

the effects on pollination caused by relatively small differences among pollinators in behavior or morphology have been observed in multiple studies (Wallace et al. 2002; Ehlers et al. 2002; Kephart and Theiss 2004; Stang et al. 2006).

During the year of the study, local abundances of Greya moths were relatively low at the two study sites in comparison to some other years (K. Rich, personal communication; J. N. Thompson, personal observation). Previous studies have shown that Greya moth populations can fluctuate considerably among years (Thompson and Cunningham 2002; Thompson and Fernandez 2006). These low numbers and the tendency of Greya moths often to move only a few times a day resulted in few visits during the surveys and experimental trials. Greya politella is a main pollinator on Lithophragma populations although its importance varies among populations depending on co-pollinators (Thompson and Pellmyr 1992; Pellmyr and Thompson 1996; Thompson and Cunningham 2002; Thompson, unpublished data). These low numbers therefore allowed an assessment of the co-pollinator assemblage structure under conditions in which presence of adult Greya, which often spend hours resting on individual flowers, were unlikely to affect visitation patterns by potential co-pollinators.

In the absence or rarity of Greya moths, natural selection might favor different floral morphologies among populations and species. Although Lithophragma is a small genus of only about seven to nine species, it differs greatly in ovary position, ranging from almost inferior to almost completely superior (actually, pseudosuperior with respect to floral development) (Kuzoff et al. 2001). One of the goals of this study was to assess whether some of these observed differences in Lithophragma floral shape may therefore be driven by geographic differences in the assemblage of co-pollinators. None of these other visitors, however, appears to be either common enough or efficient enough as a pollinator to impose strong selection on any of these four Lithophragma populations.

Divergence in floral morphology in Lithophragma could also be driven by geographic differences in patterns of sympatry among the species in this genus. In some regions, there is only one Lithophragma species, whereas in other regions, two, or even three, species co-occur. Sympatry may shape divergence in floral morphology either through facilitation or competition as suggested for other plant taxa (e.g., Armbruster et al. 1994; Schluter 2000; Moeller 2005; Ghazoul 2006). Nevertheless, the two Lithophragma species did not differ in major ways in the suite of floral visitors they attracted, although they did differ in their general performance when visited by these floral visitors.

An increasing number of studies have documented strong geographic variation in plant-animal interactions (Thompson 1997; Burdon and Thrall 2000; Benkman et al. 2001; Brodie et al. 2002; Thompson and Cunningham 2002; Zangerl and Berenbaum 2003; Lau and Galloway 2004; Siepielski and Benkman 2004; Herrera 2005; Moeller 2005; Boulay et al. 2006). These studies have suggested that, as species assemblages change, the outcomes of interactions between any pair of species may also differ. The results of this study, however, suggest that, in some interactions, geographic differences in the assemblages of co-visitors do not always result in clear differences in how selection may drive divergence among plant populations.

Acknowledgments The authors thank C.C. Fernandez for her assistance in the laboratory and greenhouse, K.A. Rich for help in the field and for valuable discussions that helped to structure the work, J.D. Hoeksema for help during manuscript revision and assistance with statistical analysis, and S. Forde, S. Dwiggins, Jeffry Karron, B. Piculell, and two reviewers for very helpful comments on the manuscript. Insect identifications were kindly provided by C.N. Evenhuis (Bombyliidae), R.R. Snelling (Hymenoptera), and C. Thompson (Diptera). We are grateful to K. Heise, who provided vegetation information for Hopland, and to Mark Stromberg at Hastings Reserve and J.H. Rohrbough, R.J. Keiffer and J.W. Marston at Hopland Field Station for assistance in many ways during work at these reserves. We especially thank J. Velzy for his assistance in the greenhouse. This work was supported by UC-MEXUS CONACYT Post-doctoral Fellowship (No. Exp. 040001) and by National Science Foundation grant DEB-0344147 and DEB-0839853. Experiments reported in this work comply the current laws of the United States of America.

Open Access This article is distributed under the terms of the Creative Commons Attribution Noncommercial License which permits any noncommercial use, distribution, and reproduction in any medium, provided the original author(s) and source are credited. 


\section{References}

Armbruster WS, Edwards ME, Debevec EM (1994) Floral character displacement generates assemblage structure of Western Australian triggerplants (Stylidium). Ecology 75:315-329

Bascompte J, Jordano P, Melián CJ, Olesen JM (2003) The nested assembly of plant-animal mutualistic networks. Proc Natl Acad Sci USA 100:9383-9387

Benkman CW, Holimon WC, Smith JW (2001) The influence of a competitor on the geographic mosaic of coevolution between crossbills and lodgepole pine. Evolution 55:282-294

Borba EL, Semir J (2001) Pollinator specificity and convergence in fly-pollinated Pleurothallis (Orchidaceae) species: a multiple population approach. Ann Bot 88:75-88

Boulay R, Coll-Toledano J, Cerdá X (2006) Geographic variations in Helleborus foetidus elaiosome lipid composition: implications for dispersal by ants. Chemoecology 16:1-7

Brodie ED Jr, Ridenhour BJ, Brodie EDIII (2002) The evolutionary response of predators to dangerous prey: hotspots and coldspots in the geographic mosaic of coevolution between garter snakes and newts. Evolution 56:2067-2082

Burdon JJ, Thrall PH (2000) Coevolution at multiple spatial scales: Linum marginale-Melampsora lini-from the individual to the species. Evol Ecol 14:261-281

Cassell DL (2002) A randomization-test Wrapper for SAS ${ }^{\circledR}$ PROCs. In: SUGI 27(251) conference proceedings. SAS Institute Inc

Chao A, Chazdon RL, Colwell RK, Shen TJ (2005) A new statistical approach for assessing similarity of species composition with incidence and abundance data. Ecol Lett 8:148-159

Colwell RK (2005) EstimateS: statistical estimation of species richness and shared species from samples. Version 7.5. In: User's guide and application. http://viceroy.eeb.uconn.edu/ EstimateS7Pages/EstS7UsersGuide/EstimateS7UsersGuide.htm

Colwell RK, Coddington JA (1994) Estimating terrestrial biodiversity through extrapolation. Philos Trans R Soc Lond B 345:101-118

Colwell RK, Mao CX, Chang J (2004) Interpolating, extrapolating and comparing incidence-based species accumulation curves. Ecology 85:2717-2727

Ehlers BK, Olesen JM, Agren J (2002) Floral morphology and reproductive success in the orchid Epipactis helleborine: regional and local across-habitat variation. Plant Syst Evol 236:19-32

Fenster CB, Armbruster WS, Wilson P, Dudash MR, Thomson JD (2004) Pollination syndromes and floral specialization. Annu Rev Ecol Evol Syst 35:375-403

Ghazoul J (2006) Floral diversity and the facilitation of pollination. J Ecol 94:295-304

Gotelli NJ, Colwell RK (2001) Quantifying biodiversity: procedures and pitfalls in the measurement and comparison of species richness. Ecol Lett 4:379-391

Guimarães PR Jr, Rico-Gray V, dos Reis SF, Thompson JN (2006) Asymmetries in specialization in ant-plant mutualistic networks. Proc R Soc Lond B 273:2041-2047

Herre EA (1993) Population structure and the evolution of virulence in nematode parasites of fig wasps. Science 259:1442-1445

Herrera CM (2005) Plant generalization on pollinators: species property or local phenomenon? Am J Bot 92:13-20

Hoeksema JD, Thompson JN (2007) Geographic structure in a widespread plant-mycorrhizal interaction: pines and false truffles. J Evol Biol 20:1148-1163

Ippolito A, Fernandes GW, Holtsford TP (2004) Pollinator preferences for Nicotiana alata, $N$. forgetiana and their $\mathrm{F}_{1}$ hybrids. Evolution 58:2634-2644

JMP (2002) JMP v 5.0.1a. SAS Institute, Cary, North Carolina
Jordano P, Bascompte J, Olesen JM (2003) Invariant properties in coevolutionary networks of plant-animal interactions. Ecol Lett 6:69-81

Kephart S, Theiss K (2004) Pollinator-mediated isolation in sympatric milkweeds (Asclepias): do floral morphology and insect behavior influence species boundaries? New Phytol 161:265-277

Kuzoff RK, Soltis DE, Hufford L, Soltis PS (1999) Phylogenetic relationships within Lithophragma (Saxifragaceae): hybridization, allopolyploidy, and ovary diversification. Syst Bot 24:598-615

Kuzoff RK, Hufford L, Soltis DE (2001) Structural homology and developmental transformations associated with ovary diversification in Lithophragma (Saxifragaceae). Am J Bot 88:196-205

Lau JA, Galloway LF (2004) Effects of low-efficiency pollinators on plant fitness and floral trait evolution in Campanula americana (Campanulaceae). Oecologia 141:577-583

Lewinsohn TM, Prado PI, Jordano P, Bascompte J, Olesen JM (2006) Structure in plant-animal interaction assemblages. Oikos 113:174-184

Mant J, Bower CC, Weston PH, Peakall R (2005) Phylogeography of pollinator-specific sexually deceptive Chiloglottis taxa (Orchidaceae): evidence for sympatric divergence? Mol Ecol 14:30673076

Moeller DA (2005) Pollinator community structure and sources of spatial variation in plant-pollinator interactions in Clarkia xantiana ssp. xantiana. Oecologia 142:28-37

Pellmyr O, Thompson JN (1996) Sources of variation in pollination contribution within a guild: the effects of plant and pollinator factors. Oecologia 107:595-604

Schluter D (2000) The ecology of adaptive radiation. Oxford University Press, Oxford

Siepielski AM, Benkman CW (2004) Interactions among moths, crossbills, squirrels, and lodgepole pine in a geographic selection mosaic. Evolution 58:95-101

Stang M, Klinkhamer PGL, van der Meijden E (2006) Size constrains and flower abundance determines the number of interactions in a plant-flower visitor web. Oikos 112:111-121

Streisfeld MA, Kohn JR (2007) Environment and pollinator-mediated selection on parapatric floral races of Mimulus aurantiacus. J Evol Biol 20:122-132

Taylor RL (1965) The genus Lithophragma (Saxifragaceae). University of California Publications in Botany, California

Thompson JN (1994) The coevolutionary process. The Chicago University Press, Chicago

Thompson JN (1997) Evaluating the dynamics of coevolution among geographically structured populations. Ecology 78:1619-1623

Thompson JN (2005) The geographic mosaic of coevolution. The Chicago University Press, Chicago

Thompson JN, Cunningham BM (2002) Geographic structure and dynamics of coevolutionary selection. Nature 417:735-738

Thompson JN, Fernandez CC (2006) Temporal dynamics of antagonism and mutualism in a geographically variable plant-insect interaction. Ecology 87:103-112

Thompson JN, Pellmyr O (1992) Mutualism with pollinating seed parasites amid co-pollinators: constraints on specialization. Ecology 73:1780-1791

Wallace HM, Maynard GV, Trueman SJ (2002) Insect flower visitors, foraging behavior and their effectiveness as pollinators of Persoonia virgata R. Br. (Proteaceae). Aust J Entomol 41:55-59

Wolfe LM, Sowell DR (2006) Do pollination syndromes partition the pollinator community? A test using four sympatric morning glory species. Int J Plant Sci 167:1169-1175

Zangerl AR, Berenbaum MR (2003) Phenotype matching in wild parsnip and parsnip webworms: causes and consequences. Evolution 57:806-815 